\title{
Effective Design and Implementation of Task-Driven Learning in High School Physics: Citing the Lesson on Composition and Resolution of Forces as a Case Study
}

\author{
Liangliang Xu, Yong Zhang, Cheng Jin
}

Weifang Experimental High School, Weifang 202600, Shandong, China

\begin{abstract}
One of the primary characteristics of the holistic module learning model is task-driven learning. In this learning model, a task is a distinct activity or collection of distinct activities designed to assist students in achieving learning objectives. The purpose of this paper is to examine the effective design and implementation of task-driven learning using the composition and resolution of forces lesson as a case study. On the basis of the lesson study, the principles of task-driven learning design are summarized and some recommendations for task-driven learning implementation are made.
\end{abstract}

Science Insights Education Frontiers 2022; 11(1):1485-1498.

Doi: 10.15354/sief.22.or004

How to Cite: Xu, L., Zhang, Y., \& Jin, C. (2022). Effective design and implementation of task-driven learning in high school physics: Citing the lesson on composition and resolution of forces as a case study. Science Insights Education Frontiers, 11(1):1485-1498.

Keywords: Task-Driven Learning, Lesson Study, Task Design, Task Implementation, Key Competencies

About the Authors: Liangliang Xu, Weifang Experimental High School, Weifang 202600, Shandong, China. E-mail: 1025643390@qq.com

Yong Zhang, Weifang Experimental High School, Weifang 202600, Shandong, China.E-mail: 824136662@qq.com 


\section{Introduction}

T OLISTIC module learning, a hot topic of discussion in China's education com1 munity, has emerged as a critical model for developing students' critical competencies. The contents of a subject are divided into large modules that correspond to the subject's major concepts, rather than into discrete and fragmented lessons, and the learning contents and activities are integrated into a holistic process that assists students in autonomously constructing their knowledge structure. Task-driven learning is a key characteristic of the holistic module learning model; it is a strategy for transforming abstract learning content into concrete learning tasks in order to increase students' engagement and motivate them to develop problem-solving abilities through exploratory and cooperative learning. The purpose of this lesson study is to investigate the effective design and implementation of task-driven learning in high school physics instruction, using the composition and resolution of forces lesson as a case study. In this paper, we expand on the lesson plan and detail a demonstration lesson on this subject. Based on the lesson study, we conclude several principles of task-driven learning design, including an emphasis on textbook content, connection to practical issues, and appropriate difficulty of tasks. Additionally, we make some recommendations for implementing task-driven learning, including allowing sufficient freedom of inquiry, providing appropriate guidance, emphasizing the trial process, and encouraging student interaction.

\section{Task-Driven Learning Design}

The 2017 Edition of the Curriculum Standards for Senior Secondary School Physics (2018) states that the goals of the high school physics curriculum are to reflect the essence of physics, to maximize its educational value in terms of physical concepts, scientific thinking, scientific exploration, scientific attitude, and responsibility, to play a unique role in the development of students' key competencies, and to lay the groundwork for students' lifelong growth in order to meet the challenges of social development in the 21 st century. Additionally, the document suggests that diverse teaching methods be developed to assist students in comprehending fundamental physics theories, examining nature holistically, developing scientific thinking, and enhancing their capacity for scientific inquiry and problem solving. To foster students' capacity for

Correspondence to: Cheng Jin, Weifang Experimental High School, Weifang, 202600, Shandong, China. E-mail: 40836472@qq.com

Conflict of Interests: None.

(c) 2022 Insights Publisher. All rights reserved.

(c) 1 (i) $\$$ Creative Commons NonCommercial CC BY-NC: This article is distributed under the terms of the Crea-
tive Commons Attribution-NonCommercial 4.0 License (http://www.creativecommons.org/licenses/by-
nc/4.0/) which permits non-commercial use, reproduction and distribution of the work without further permission provided
the original work is attributed by the Insights Publisher. 
self-directed learning, it is necessary to create learning environments that encourage active participation, a willingness to explore and experiment, and critical thinking; To foster students' awareness of social participation and responsibility, the curriculum design should emphasize the curriculum's connection to life, society, and scientific and technological development. This will keep students fully informed of significant scientific achievements and new scientific ideas brought about by contemporary scientific and technological advances, as well as the distinctions made by the technological application of physics. Additionally, to maximize the effectiveness of academic assessments in promoting students' learning and development, a diagnostic and incentive curriculum assessment system combining summative and formative assessments should be established. The assessment system should be multidimensional and equipped with scientific tools in order to account for individual differences and help students develop their selfconcept and self-confidence.

The learning tasks are determined by the subject-related competency requirements, which are based on curriculum standards and textbook content. The module, "Interaction-Force," in the Ordinary High School Compulsory Physics Textbook, 2019 Edition Volume 1 (2019), is critical to the theory of interaction and a critical component of the view of motion and interaction. Section 4, Composition and Resolution of Forces, provides a tool for calculating forces and acts as a critical link between the preceding three sections (on gravity and elasticity, friction, and Newton's third law, respectively) and Section 5, Balance of Concurrent Forces.

Composition and Resolution of Forces are divided into two sections in textbooks prior to the 2019 edition, and the experiment on the rule of resultant force is a confirmatory one titled "Verification of the Parallelogram Rule of Force." Nonetheless, in the new textbook (2019 edition), the confirmatory experiment is replaced by an exploratory one titled "Exploration of the Rule of Composition of Forces with a Certain Angle to Each Other," which is intended to fulfill the new curriculum design requirement of developing students' capacity for scientific inquiry. However, many teachers are unable to determine the underlying reason for this change, and as a result, they continue with their previous practice of conducting a confirmatory experiment in the first session and, more problematically, lecturing on second-order inference of force composition and resolution in the second session, addressing questions such as "What is the range of the resultant of two forces?" "How do I solve for multiple solutions, two solutions, non-solutions, and the optimal component force value given the resultant force?" "How is the magnitude of the resultant force related to the magnitude of the component force?" "How is the magnitude of the resultant force (or component force) related to the included angle's size?" Abstract and obtuse, such tedious technical generalizations do little to pique students' interests, much less assist them in meeting learning objectives.

The Composition and Resolution of Forces lesson design aims to maximize students' acquisition of knowledge and skills but also to foster the development of critical competencies such as scientific inquiry, scientific reasoning, scientific demonstration, critical thinking, innovation, and a scientific attitude and responsibility. To accomplish these goals, we designed this lesson around task-driven learning, with the primary 
objective being to create a scientific cable-stayed bridge model with a high bearing capacity. Six learning activities comprise the task.

The first activity introduces the experiment and provides students with a fundamental understanding of the relationship between resultant force and component force. The class begins with a small game in which two students are asked to lift a parcel using two long ropes with a large included angle between the two component forces (undoubtedly, lifting the parcel in this manner will require considerable effort), while the teacher can easily lift it with one hand. Students' and teachers' forces have the same effect. Thus, the resultant and component forces concepts are introduced, and students are prompted to consider the relationship between the resultant and component forces: Equivalent substitution Students can easily conclude from experience that the composition of two forces is not equal to the sum of their values, which leads to the topic of study for the current lesson, namely the rule of force composition.

In activity two, the class clarifies and interprets the task's objective.

In activity three, students create experiment plans, organize themselves into experimental groups, and practice the four fundamental components of scientific inquiry: questions, evidence, interpretation, and communication.

Question: If the composition of two forces at an angle to one another is not equal to the sum of their values, what is the rule?

Evidence: The class creates plans, experiments in groups, hypothesizes, and verifies using the equipment provided (wood board, rubber band, spring $d y$ namometer, triangular plate, and pushpins, for example).

Interpretation: How will the hypothesis be proven? What can be deduced from the experiment? Can they provide an explanation for the questions posed in the lesson's introduction? Can they account for the composition of forces in other manifestations?

Communication: The class analyzes the experimental conclusion and its effectiveness. The teacher should explain to students that the parallelogram rule was not discovered in a single or two experiments and provide a brief overview of the work of Steven in the Netherlands and Newton in the United Kingdom in order for students to develop a scientific attitude and respect for scientific rules and laws.

Students independently design experiments using the teacher-provided equipment. The questions are open for discussion and do not have predetermined answers, giving students ample opportunity for creativity and innovation. Additionally, hypotheses and verification are unresolved issues. The importance of students as class leaders is emphasized. Self-directed learning, cooperative study groups, and other strategies are used to foster a student-centered classroom environment.

Students are required to study the principle of the cable-stayed bridge in activity four. The teacher demonstrates the structure and benefits of cable-stayed bridges, using the world-famous Hong Kong-Zhuhai-Macao Bridge's channel bridge as an ex- 
ample. When students are analyzing the fundamentals of cable-stayed bridge mechanics using the parallelogram rule of force, the teacher can inspire them by asking why such a long and heavy bridge deck does not bend or fall and why the cable tower does not tilt or break under extreme stress.

Students are required to construct a model cable-stayed bridge using wooden strips, cotton thread, and hot glue guns for activity five. Experimental teams will compete to create the most scientifically and visually appealing bridge model with the greatest bearing capacity.

The process of creating a cable-stayed bridge model is one of putting theory into practice. On the other hand, practice serves as a means of determining whether the theory is correct. During the model-building process, theory and practice validate one another.

Activity six provides an opportunity for experimental groups to display their Hong Kong-Zhuhai-Macao Bridge models and analyze the bridge's mechanics. The teacher should not be concerned with the quality of the models created by students, but rather should foster a relaxed and inspiring research environment in which students can express themselves freely and bravely. At this point, students may inquire, "Why isn't the bridge deck falling?" The answer is that the resultant force of multiple steel cables is oriented upward, and the resultant force is substantial. "How come the cable tower does not tilt?" (The answer is that the resultant force is oriented downward.) "Why are the majority of stay cables symmetrical?" (The answer is to ensure that the resultant force is vertical.) "Can the stay cables be asymmetrical?" (The answer is that by adjusting the tension on the steel cables, we can cause the resultant force to be oriented downward.) "How come cable towers are typically so tall?" (The answer is that when cable tensions are held constant, the smaller the included angle between component forces, and the greater the resultant force, and vice versa.) These questions are directly related to the application of force composition or force resolution and are easily understood by all students. Students acquire knowledge and develop skills and competencies while completing the assignment.

\section{A Record of the Demonstration Lesson on Composi- tion and Resolution of Forces}

\section{Activity One: A Lesson Introduction-The Relationship between the Resultant Force and the Component Force}

Two strong students were chosen to pull up a mysterious parcel using two long ropes at an acute angle to one another, but they were unsuccessful. They could pull it up as they got closer together and the angle between the ropes became smaller. The teacher then approached the parcel and effortlessly picked it up with one hand. At this point, the teacher posed three questions: "How are the two students able to lift the parcel as the 
angle between the two ropes narrows?" "Is that because they suddenly became stronger?" What is the composition rule for two forces that are at an angle to one another?

Observers' Comment: The teacher was successful in introducing the topic of study to the class - that is, the rule of composition of forces at a certain angle to one another, stimulating students' desire to explore through self-created teaching aids, generating cognitive conflicts, and exposing students to a specific example.

\section{Activity Two: Identifying the Objective and Task of the Lesson}

Students gained an understanding of the task and objectives of the current lesson by experimenting with the rule of composition of two forces at a certain angle to one another, building a cable-stayed bridge model with excellent bearing capacity based on the rule, and elaborating on the model's advantages.

Observers' Comments: the module's learning objectives were interpreted in such a way that students could complete the exploratory task within the context of the module as a whole, avoiding fragmented learning. Additionally, students were fully aware of what they needed to accomplish in class after identifying the lesson's objectives and tasks.

\section{Activity Three: Exploring the Rule of Composition of Forces at a Certain Angle to Each Other}

Students discussed and optimized their experiment plans in groups before conducting the experiment. After the experiment concluded, the experimental group demonstrated the experiment's process and conclusion to the class.

Students: Experiment plans were developed following extensive group discussion. Then, students attempted to exchange their responses to the three questions posed by the teacher in activity one.

The Teacher: The teacher guided the students in reflecting on their incorrect responses to his three questions and then having them discuss their experimental plans in groups to finalize them.

Students: Using equipment provided by the teachers (wood board, rubber band, spring dynamometer, triangular plate, pushpins, etc.), group members shared the work and collaborated to conduct the experiment, record the data, 
draw diagrams, and conduct analysis. Three groups were invited to the classroom podium to present their experiments.

Group Two's Presentation: Their experimental results confirmed that the parallelogram rule applies to the composition of forces. This group connected the two component and resultant forces, forming what appeared to be a parallelogram, and then verified their connection by translating the triangular plate.

Group Seven's Presentation: Their experimental results confirmed that the parallelogram rule applies to the composition of forces. This group constructed a parallelogram with two component forces as adjacent sides, with the parallelogram's diagonal essentially corresponding to the resultant force. Group Nine's Presentation: Their experimental results demonstrated that the parallelogram rule does not apply to the composition of forces. Three trials were conducted by this group. They drew diagrams from the experiment data, but none were parallelograms.

The Teacher: after conducting at least three trials, the other teams reported the same experimental result as group two and group seven. This indicated that the experiment was successful in convincing students that the parallelogram rule governs the composition of forces. Students were prompted to consider the possible causes of Group Nine's incorrect result. Finally, the teacher informed students about the history of the rule of force composition, which was fraught with twists and turns, in order to emphasize to students that deriving a rule is never simple and requires a commitment to science.

Observers' Comments: Due to their cognitive limitations, tenth graders require guidance during exploratory experiments to ensure a controlled outcome. As a result, prior to the experiment, the teacher needed to guide students in locating answers to the following three questions: How can we ensure that the resultant force and component force are substituted in an equivalent manner? How do you calculate the magnitude of a force? How can the direction of force be determined? Additionally, students must discuss and optimize their experiment plans in groups prior to conducting the experiment. Students' natural engagement in the exploration indicated that they had received some pre-class instruction, but at a level appropriate for their age. The teacher was extremely concerned with the students' exploration process and allowed ample time for independent inquiry. Most importantly, the group presentation of results allowed students to express themselves freely and aided in the development of students' communication skills. Finally, students were introduced to the history of physics.

\section{Activity Four: Examining the Mechanical Theory of Cables Stayed Bridge}


This activity occurred following students' exploration of the rule of force composition. The teacher introduced the cable-stayed bridge structure briefly through pictures, and students used their prior knowledge of the rule of force composition to analyze the cable-stayed bridge's mechanical theory. In activity five, students would further their understanding of the theory by building the model. To maintain the integrity of the investigation, the transition from activity 4 to activity 5 was seamless.

\section{Activities Five and Six: Making a Scientific Cable- Stayed Bridge Model with Perfect Bearing Capacity, as well as Discussing the Benefits of the Hong Kong- Zhuhai-Macao Bridge's Channel Bridge}

The Teacher: The cable-stayed bridge structure was briefly explained through photographs, and students were provided with materials (wood strips, connecting wire, hot glue gun, knife, and thread) for building the models.

Students: Students first analyzed the mechanical characteristics of cablestayed bridges before creating group models of cable-stayed bridges. All groups were invested in and fully engaged in the creation of models, which took on a variety of forms. Following that, four groups presented in turn their cable-stayed bridge models and discussed their advantages using the knowledge gained in this class. The other groups posed questions and justified their inquiries.

The Model by Group One: It possessed the greatest number of stay cables and thus the greatest bearing capacity. This is because the resultant force generated by each group of stay cables is determined by the stay cable's bearing capacity. The more stayed cable groups there are, the greater the bearing capacity.

The Model by Group Three: The height of the cable tower model resulted in a high bearing capacity because when the bearing capacity of the stay cable is fixed, the smaller the included angle between the stay cables, the greater the resultant force according to the parallelogram rule of force, resulting in a higher bearing capacity.

The model by Group Five: The cable tower model's stability is due to the symmetrical distribution of stay cables. The reason for this was that the angles between the stay cables and the cable tower were maintained consistent$l y$, and the resulting force was oriented downward on the cable tower.

The Model by Group Nine: Despite the asymmetry of the stay cables, the cable tower did not collapse. The reason for this was that the cable force could be adjusted by fine-tuning the bolts. As long as the cable tower's force is directed downward, it will not topple over. 
The Teacher: The teacher then led a discussion with the class about why it took the two students so long to lift the parcel in activity one. Finally, students were asked to summarize what they learned in class and assess their achievement of learning objectives during the final ten minutes.

Observers' Comments: The assignment to design and construct a cablestayed bridge model aided in the development of students' practical abilities. Their enthusiasm for learning was piqued by the situational experience. Apart from the acquisition of knowledge through model making, the teacher emphasized students' exchange and interaction. Additionally, some groups incorporated information from the classroom presentation and interaction into their bridge models after all class activities were completed. The teacher was wise not to interrupt their discussions and attempts to improve, but to allow them sufficient time to continue.

All students actively participated in class and focused on the task at hand, demonstrating the effectiveness of task-driven learning. While completing the task, students met their learning objectives in terms of knowledge acquisition and the development of scientific thinking. It was a student-centered class in which students were fully empowered and trusted, with ample time for discussion, exploration, and exchange.

\section{Reflections on the Demonstration Lesson}

\section{Analysis of Data from Observations of the Demonstra- tion Lesson}

Table 1, a summary of data from observations of the demonstration lesson on composition and resolution of forces, shows that task-driven learning is effective in the overall implementation of the lesson (Figure 1). However, there is still potential for development in terms of learning objectives; students' critical thinking and autonomous knowledge production require more valuable questions.

\section{The Teacher's Reflections on Task-Driven Learning}

(i) The key to achieving task-driven learning is to link activities to students' prior experience, practice, current societal challenges, or cutting-edge research and technology. Tasks should be useful and entertaining to increase student participation, which are two aspects of the task in this demonstration lesson.

(ii) Task effectiveness is measured by whether or not learning objectives are met. Designing a task is not a mechanical process. All activities should be required to complete a task in order to achieve learning objectives.

(iii) In competence-oriented task activities, teachers' trust in pupils frequently leads to unexpected outcomes. Students' successful learning can be aided by their interest in science, as well as their investigation of methodology and major topics in the discipline. 
Xu et al. (China). Task-Driven Learning in High School Physics.

\begin{tabular}{|c|c|c|c|c|c|c|c|}
\hline Time & \multicolumn{7}{|c|}{ November $23^{\text {rd }}, 2021$} \\
\hline School & \multicolumn{7}{|c|}{ Weifang Experimental High School } \\
\hline Class/Grade & \multicolumn{7}{|l|}{ Class 32, Grade 10} \\
\hline Teacher & \multicolumn{7}{|l|}{ Cheng Jin } \\
\hline Lesson & \multicolumn{7}{|c|}{ Composition and resolution of forces } \\
\hline Subject & \multicolumn{7}{|l|}{ Physics } \\
\hline \multirow[b]{2}{*}{ Perspectives } & & Observers & Assessmen & coring $(0-5$ & & & \\
\hline & $\begin{array}{l}\text { Observation } \\
\text { Record }\end{array}$ & $\begin{array}{l}\text { Observer } \\
1\end{array}$ & $\begin{array}{l}\text { Observer } \\
2\end{array}$ & $\begin{array}{l}\text { Observer } \\
3\end{array}$ & $\begin{array}{l}\text { Observer } \\
4\end{array}$ & $\begin{array}{l}\text { Average } \\
\text { Scores }\end{array}$ & $\begin{array}{l}\text { Average } \\
\text { Scores } \\
\text { of Each } \\
\text { Activity } \\
\end{array}$ \\
\hline \multirow{3}{*}{$\begin{array}{l}\text { Lesson } \\
\text { Introduction }\end{array}$} & $\begin{array}{l}\text { 1. Does the introduction } \\
\text { help motivate students' } \\
\text { active learning? }\end{array}$ & 5 & 5 & 4 & 5 & 4.75 & \multirow[t]{3}{*}{4.75} \\
\hline & $\begin{array}{l}\text { 2. Is the introduction closely } \\
\text { related to learning con- } \\
\text { tents? }\end{array}$ & 5 & 5 & 4 & 4 & 4.5 & \\
\hline & $\begin{array}{l}\text { 3. Are the questions raised } \\
\text { in the introduction reviewed } \\
\text { and answered in the end? }\end{array}$ & 4 & 4 & 4 & 4 & 4 & \\
\hline \multirow{4}{*}{$\begin{array}{l}\text { Learning } \\
\text { Objectives }\end{array}$} & $\begin{array}{l}\text { 1. Are learning objectives } \\
\text { scientifically appropriate? }\end{array}$ & 5 & 4 & 5 & 4 & 4.5 & \multirow[t]{4}{*}{4.5} \\
\hline & $\begin{array}{l}\text { 2. Do learning objectives } \\
\text { follow the principle of } \\
\text { knowledge internalization } \\
\text { and generation in practice? }\end{array}$ & 5 & 5 & 4 & 4 & 4.5 & \\
\hline & $\begin{array}{l}\text { 3. Are learning objectives } \\
\text { assessable? }\end{array}$ & 5 & 5 & 5 & 5 & 5 & \\
\hline & $\begin{array}{l}\text { 4. Are learning objectives } \\
\text { student-centered? }\end{array}$ & 5 & 5 & 5 & 5 & 5 & \\
\hline \multirow{2}{*}{$\begin{array}{l}\text { Situation } \\
\text { Setting } \\
\text { in the task }\end{array}$} & $\begin{array}{l}\text { 1. Is situation setting related } \\
\text { to life, society, and scientific } \\
\text { and technological develop- } \\
\text { ment? }\end{array}$ & 5 & 5 & 5 & 4 & 4.75 & \multirow[t]{2}{*}{4.875} \\
\hline & $\begin{array}{l}\text { 2. Is the situation experi- } \\
\text { enced by students? }\end{array}$ & 5 & 5 & 5 & 5 & 5 & \\
\hline \multirow{4}{*}{ Task-driven } & $\begin{array}{l}\text { 1. Is everyone involved in } \\
\text { the task? }\end{array}$ & 5 & 5 & 4 & 5 & 4.75 & \multirow[t]{4}{*}{4.8125} \\
\hline & $\begin{array}{l}\text { 2. Are students involved } \\
\text { throughout the lesson? }\end{array}$ & 5 & 5 & 5 & 5 & 5 & \\
\hline & $\begin{array}{l}\text { 3. Do students have the } \\
\text { freedom of choosing their } \\
\text { own ways of implementing } \\
\text { the task? }\end{array}$ & 5 & 5 & 5 & 5 & 5 & \\
\hline & $\begin{array}{l}\text { 4. Is students' learning self- } \\
\text { directed? }\end{array}$ & 4 & 5 & 5 & 5 & 4.75 & \\
\hline \multirow{4}{*}{$\begin{array}{l}\text { Effectiv- } \\
\text { ness of Task }\end{array}$} & $\begin{array}{l}\text { 1. Are exploration activities } \\
\text { centered on the actualiza- } \\
\text { tion of learning objectives? }\end{array}$ & 5 & 5 & 5 & 5 & 5 & \multirow[t]{4}{*}{4.875} \\
\hline & $\begin{array}{l}\text { 2. Achievement of objec- } \\
\text { tives after the task fulfilled? }\end{array}$ & 5 & 5 & 5 & 5 & 5 & \\
\hline & $\begin{array}{l}\text { 3. Does students' newly- } \\
\text { generated questioning point } \\
\text { to learning objectives? }\end{array}$ & 4 & 5 & 5 & 5 & 4.75 & \\
\hline & $\begin{array}{l}\text { 4. Is the task informative, } \\
\text { cooperative, and education- } \\
\text { al? }\end{array}$ & 4 & 5 & 5 & 5 & 4.75 & \\
\hline \multirow{4}{*}{$\begin{array}{l}\text { Teaching } \\
\text { Efficacy }\end{array}$} & $\begin{array}{l}\text { 1. Does the teacher put } \\
\text { balanced weight on } \\
\text { knowledge imparting, meth- } \\
\text { odology, results and learn- } \\
\text { ing process? }\end{array}$ & 5 & 5 & 5 & 5 & 5 & \multirow[t]{4}{*}{4.6875} \\
\hline & $\begin{array}{l}\text { 2. Does the teacher have } \\
\text { enough confidence in stu- } \\
\text { dents and give them } \\
\text { enough freedom in explora- } \\
\text { tion? }\end{array}$ & 5 & 4 & 5 & 5 & 4.75 & \\
\hline & 3. Scientific errors avoided? & 5 & 5 & 5 & 4 & 4.75 & \\
\hline & $\begin{array}{l}\text { 4. Any valuable questions } \\
\text { posed to induce students' } \\
\text { reflection \& construction? }\end{array}$ & 5 & 4 & 4 & 4 & 4.25 & \\
\hline
\end{tabular}



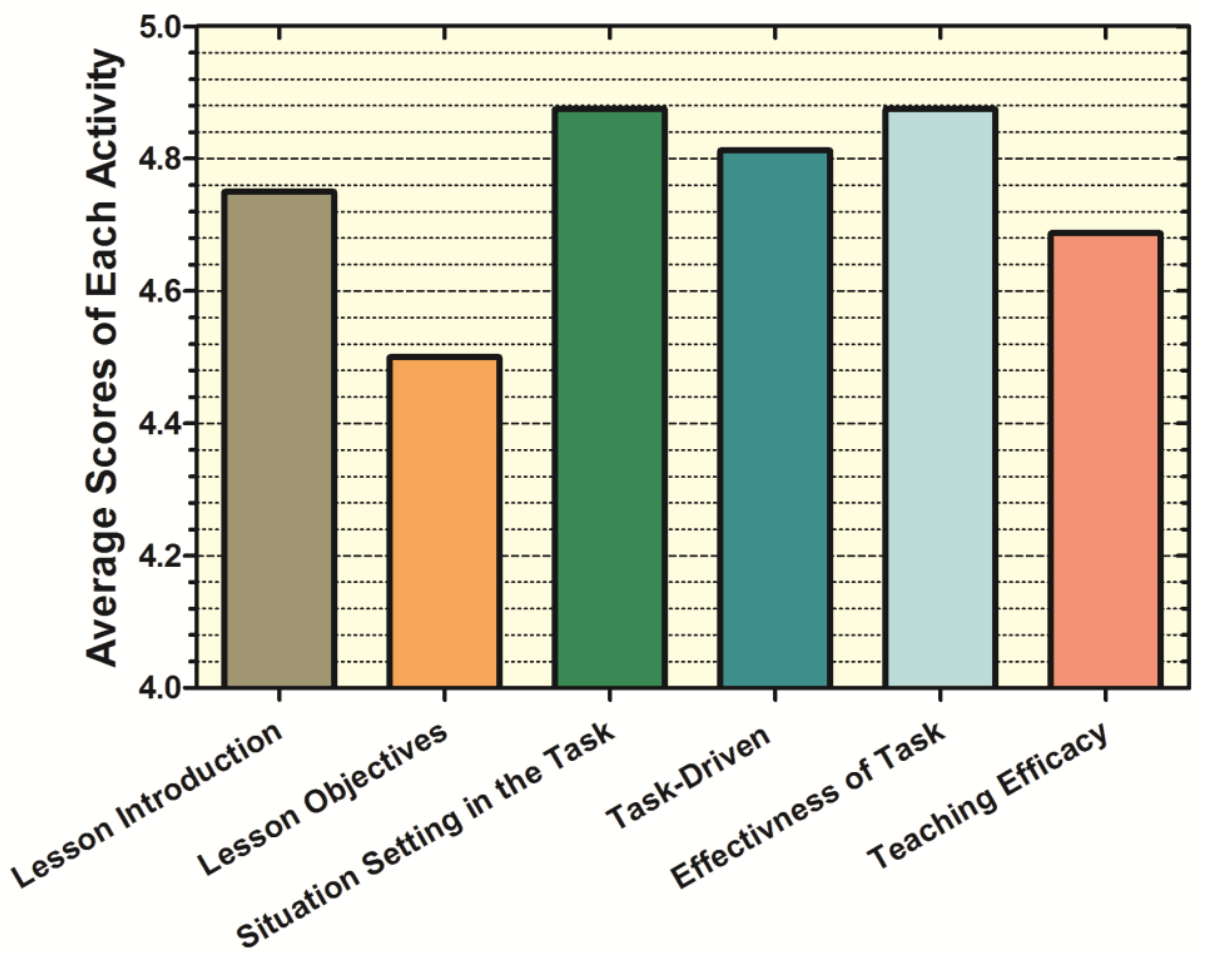

Figure 1. Result of Observations.

(iv) Prior to the class, assignment design requires an understanding of the students' knowledge background. For example, in this situation, tenth graders are not yet proficient in trigonometric functions, so students received suitable trigonometric function training prior to class to better address physics challenges.

\section{Conclusions of the Lesson Investigation}

The results of this lesson show that task-driven learning can inspire students' enthusiasm for investigation, equip students with a broad vision of inquiry, and help them build higher-order thinking skills. Students are completely involved in classroom activities and acquire a pro-active learning attitude through task-driven learning. It has become a necessary step in achieving crucial competencies.

\section{(i) Task-Driven Learning Design Principles.}

Effective task-driven learning, according to Xia (2018) of the Shanghai Academy of Educational Sciences, can offer learners a broad vision of exploration. It can help stu- 
dents not just become more self-motivated but also engage in more persistent and indepth thinking and inquiry. Based on the summary of data from the observations of the demonstration lesson on composition and resolution of forces, we conclude the principles of task-driven learning design as follows:

(ii) The importance of textbooks in task design should be emphasized.

Experts undertake extensive analysis and demonstration of the chosen cases when compiling textbooks, so the contents of textbooks are worth studying before planning the work. To avoid the impact of teachers' arbitrary selections, curriculum criteria should be reviewed to ensure that the job is founded on a realistic foundation.

(iii) The tasks should be goal-oriented.

In task design, the teacher must specify the learning objectives, concrete requirements, and basic procedures so that students may concentrate on task implementation and know how to proceed smoothly. As a result, even when students are performing independent exploration, the lesson can proceed in a structured manner.

(iv) Tasks should be linked to real-world concerns.

One of the most important reasons for studying physics is to find solutions to difficulties that arise in everyday life and at work. Only when the work is linked to reality can children develop a great drive to investigate and feel a powerful feeling of accomplishment when they attain the desired outcomes. Students can engage in a more in-depth learning process by using a reality-based assignment that takes them from phenomenon to questioning, analysis, experimentation, transfer, and transformation.

(v) The tasks should be hard while also being appropriate for the pupils' academic level.

Teachers must include a certain amount of difficulty in activities so that students will try to make the most of what they already know and collaborate with their classmates. Students improve their communication and teamwork abilities as they complete activities. The task's difficulty, on the other hand, should not exceed the students' existing academic level. Their enthusiasm for studying will wane if they feel overwhelming frustration and futility.

\section{Suggestions for Task-Driven Learning Implementation}

Task-driven learning requires effective implementation to ensure that learning objectives are met. As a result, we offer some recommendations for maximizing the benefits of task-driven learning for students.

(i) Providing Pupils with the Ability to do Independent Research.

Students are motivated to achieve a clear and precise goal through self-directed inquiry and group cooperation in task-driven learning. The teacher should have complete faith 
in their ability and knowledge. Students would have simply followed the teacher's conduct in the current lesson study if the teacher had directly instructed the students on how to do the experiment by playing videos or personally demonstrating it, and the experiment would have turned out to be a confirmatory rather than an exploratory one, which did not help cultivate students' ability to divergent think, inquire, and cooperate. As a result, teachers must use extreme caution when interfering with pupils' independent activities.

\section{(ii) Providing Suitable Guidance to Students.}

Showing faith in kids, on the other hand, does not excuse teachers' inaction. The teacher should be involved in the students' group work as an advisor and observer while they complete the task. They may run into a variety of issues during their exploration, some of which they will be unable to address on their own. Rather than providing students with ready solutions, teachers should give them some indications ahead of time and help them think about what to do next.

\section{(iii) Paying Attention to the Job Fulfillment Exploration Process.}

The exploratory process of completing the job is crucial in the development of pupils' overall competency. In class, the teacher should give pupils enough time to complete their work. Some groups and students may not be able to complete the activity within the allotted time. The teacher should not pressure students to finish the assignment by telling them what to do in these situations. Instead, the teacher should emphasize to them that the work they put in during the learning process is more important than the outcome. Even if pupils do not complete the job to the required standard, their competence has increased, and their curiosity about the subject has remained.

\section{(iv) Encouraging Collaboration and Sharing Among Study Groups.}

When students complete exploratory tasks successfully, they are eager to share their findings. The group responds to questions from the rest of the class, explains how they apply the theory to group work, and listens to comments and ideas from the other groups during their presentation of their work results. Following the debate and communication, the group members will be motivated to make improvements to their work. This is a good example of using freshly gained knowledge to solve new difficulties.

\section{References}

People's Education Press. (2019). Ordinary High School Compulsory Physics Textbook 2019
Edition Volume 1. Beijing: People's Education Press. 
Xu et al. (China). Task-Driven Learning in High School Physics.

Ministry of Education of China. (2018). Curriculum Standards for Senior Secondary School Physics. Ministry of Education of China.

Xia, X.M. (2018). Project-Based Learning (PBL)

Design: International and Local Practice from the Perspective of Learning Competence. Beijing: Educational Science Publishing House.

Received: 11 January 2022

Revised: 01 February 2022

Accepted: 10 February, 2022 